\title{
EFFICACY OF PROPHYLACTIC CORTICOSTEROIDS PRIOR TO CESAREAN SECTION TO PREVENT RESPIRATORY COMPLICATION
}

\author{
By
Amir Mohamed Said Ali, Mohamed Khaled Mostafa and Mohamed Mohamed Farahat

Department of Obstetrics and Gynecology, Faculty of Medicine, Al-Azhar University

Corresponding author: Amir Mohamed Said Ali, E-mail: amiratwa1988@ gmail.com

\begin{abstract}
Background: Cesarean section (CS) is a risk factor for the development of neonatal respiratory complications, mostly respiratory distress syndrome (RDS) and transient tachypnea of the new-born, both in term and preterm infants. Infants born at term by elective cesarean delivery are more likely to develop respiratory morbidity than infants born vaginally.
\end{abstract}

Objective: To assess the effect of prophylactic corticosteroid administration before elective cesarean section at term, as compared to usual management without corticosteroids, in reducing neonatal respiratory morbidity and admission to special care with respiratory complications.

Patients and methods: This was a prospective study that was conducted on 200 women from the Out-Patient Clinic at Al-Hussein Hospital, Al-Azhar University from September 2018 to November 2019. Randomized controlled trials comparing prophylactic antenatal corticosteroid administration (dexamethasone) with placebo or with no treatment, given before elective cesarean section at term (at or after 37 weeks of gestation).

Results: PG represented $60 \%$ of 1 st group while represented $50 \%$ of 2 nd group without significant difference between them. There was no significant difference between groups as regard co-morbidity. There was no significant difference between groups regard causes of CS, and the major causes were previous CS and placenta previa. There was no significant difference between groups as regard postpartum hemorrhage or maternal complication in general. APGAR1 was significantly higher among corticosteroid group. Overall respiratory complication was significantly lower among corticosteroid group, respiratory distress (RD), need of neonatal intensive care unit (NICU) and mechanical ventilation and mortality were lower among the same group than control but not significantly.

Conclusion: A single course of corticosteroids (four $6 \mathrm{mg}$ doses of dexamethasone administered intramuscular every 12 hours) should be considered for women undergoing planned cesarean at 37 or more weeks' gestation.

Keywords: Corticosteroids, Cesarean Section, Respiratory Complication.

\section{INTRODUCTION}

Cesarean section rate has been increasing. It represents $30 \%-40 \%$ of births delivering methods, approximately half of which are elective cesarean delivery. This may be due to changing practice in the management of previous caesarean and breech presentation as well as increased choice of women. Improved techniques of control of hemorrhage, 
infection, and thromboembolism have increased safety of the procedure. As a result obstetricians and pregnant women have reduced threshold for choosing it. However although maternal risks have decreased, the effect of surgical delivery on the baby before due date continues to be debated (Martin et al., 2015 and Nada et al., 2016).

Prophylactic corticosteroids in preterm pregnancies accelerate lung maturation and reduce the incidence of respiratory morbidity. Cesarean section is a risk factor for the development of neonatal respiratory complications, mostly respiratory distress syndrome (RDS) and transient tachypnoea of the new-born, both in term and preterm infants (Roberts et al., 2017).

Infants born at term by cesarean delivery are more likely to develop respiratory morbidity than infants born vaginally, and this risk increases furthermore for the subgroup of children born after elective cesarean section, i.e. before onset of labor, with potentially severe implications (Ahmed et al., 2015).

The risk is decreasing with advancing gestational age, and infants born between $37+0$ and $37+6$ weeks are at 1.7 times more risk for respiratory complications than those born between $38+0$ and $38+6$ weeks, which in turn are at 2.4 times more risk than the infants born between $39+0$ and 39+6 weeks (Shamseer et al., 2015).

If women were given two intramuscular injections of $12 \mathrm{mg}$ of dexamethasone, two doses for $48 \mathrm{hrs}$., the rates of admissions were at 37 weeks, $2.8 \%$ at 38 weeks, and $0.6 \%$ at 39 weeks. Although none of the babies in the control group died admission increase parental anxiety, the cost to nursery unit and invasive procedures including artificial ventilation giving mothers dexamethasone, two doses before elective section halved neonatal morbidity (Prefumo et al., 2016).

In view of this evidence, it is currently recommended that elective cesarean section should be deferred to 39 weeks. However approximately $10 \%-15 \%$ of woman planed for $\mathrm{C} / \mathrm{S}$ may deliver before 38 weeks, and there may be concern on waiting in the presence of specific indications or previous history. Respiratory morbidity in cases of term elective cesarean birth appears to have a different pathophysiology than in preterm birth, and retention in the lungs being the most likely cause (Ceriani, 2015).

The aim of this study was to assess the effect of prophylactic corticosteroid administration before elective cesarean section at term, as compared to usual management without corticosteroids, in reducing neonatal respiratory morbidity and admission to special care with respiratory complications.

\section{PATIENTS AND METHODS}

This was a prospective study conducted on 200 women from the OutPatient Clinic at Al-Hussein Hospital, AlAzhar University from September 2018 to November 2019.

Randomized controlled trial compared prophylactic antenatal corticosteroid administration (dexamethasone) with placebo or with no treatment, given before elective cesarean section at term (at or after 37 weeks of gestation). 
The record of all (200) women were divided into two equal groups:

Group A had received two doses of prophylactic corticosteroid prior to delivery and Group B had not received it.

\section{Inclusion criteria:}

Women with singleton pregnancies at term (complete 37+0- 39 weeks), age from 18 years to 35 years, patients under regional anesthesia, and women with confirmed dates (early ultrasound scan 1st and 2nd trimester, or sure about LMP).

\section{Exclusion criteria:}

Women with DM, age more than 36 years old, women with congenital malformed babies, IUGR fetuses, women less than 37 weeks, multiple pregnancies, and women received dexamethasone, two doses during pregnancy due to other causes and women refused this intervention.

An approval of the study was obtained from Al- Azhar University academic and ethical committee. Every patient signed an informed written consent for acceptance of the operation.

All patients were subjected to complete medical history taking and clinical examination. Investigations included: Complete blood picture, obstetrics ultrasound to confirm gestational age, urine analysis, random blood sugar, coagulation profile, liver functions tests and kidney function tests. All women delivered by Elective CS between 37 weeks to 39 weeks of pregnancy, and follow-up for the patient and neonates.

Maternal and neonatal medical records were reviewed and all required information was documented whose primary outcome measure was to see the number of babies with respiratory complications in each group and secondary outcome measure was to compare difference in nursery admission and total hospital stay in both groups.

\section{Statistical analysis:}

Data collected throughout history, basic clinical examination, laboratory investigations and outcome measures coded, entered and analyzed using Microsoft Excel software. Data were then imported into Statistical Package for the Social Sciences (SPSS version 20.0) software was represented for analysis. According to the type of data qualitative were represented can as number and percentage, quantitative continues group were represented by Mean \pm SD. The following tests were used to test differences for significance; difference and association of qualitative variable by Chi square test $\left(\mathrm{X}^{2}\right)$. Differences between quantitative independent groups by $t$ test. $P$ value was set at $<0.05$ for significant results. 


\section{RESULTS}

Age was distributed as 27.0 \pm 2.71 and $26.6 \pm 3.85$ respectively without significant difference between groups and gestational age (GA) was distributed as $35.95 \pm 1.3$ and $36.02 \pm 1.12$ respectively between groups without significant difference (Table 1).

Table (1): Age and GA distribution between studied groups

\begin{tabular}{|c|c|c|c|}
\hline Groups & $\begin{array}{c}\text { Corticosteroid } \\
\text { Group (100) }\end{array}$ & $\begin{array}{c}\text { Control } \\
\text { Group }(\mathbf{1 0 0})\end{array}$ & P \\
\hline Age & $\mathbf{2 7 . 0} \pm \mathbf{2 . 7 1}$ & $\mathbf{2 6 . 6} \pm \mathbf{3 . 8 5}$ & $\mathbf{0 . 4}$ \\
\hline GA & $\mathbf{3 5 . 9 5} \pm \mathbf{1 . 3}$ & $\mathbf{3 6 . 0 2} \pm \mathbf{1 . 1 2}$ & $\mathbf{0 . 6 8 4}$ \\
\hline
\end{tabular}

PG represent $60 \%$ of 1 st group while represent $50 \%$ of 2 nd group without significant difference between them (Table 2).

Table (2): Parity distribution between studied groups

\begin{tabular}{|c|c|c|c|c|c|}
\hline \multirow{2}{*}{ Parity } & Groups & $\begin{array}{c}\text { Corticosteroid } \\
\text { Group (100) }\end{array}$ & $\begin{array}{c}\text { Control } \\
\text { Group (100) }\end{array}$ & \multirow{2}{*}{ Total } & \multirow{2}{*}{ P } \\
\hline \multirow{2}{*}{ PG } & $\mathbf{N}$ & $\mathbf{6 0}$ & $\mathbf{5 0}$ & $\mathbf{1 1 0}$ & \\
\cline { 2 - 5 } & $\%$ & $\mathbf{6 0 . 0 \%}$ & $\mathbf{5 0 . 0 \%}$ & $\mathbf{5 5 . 0 \%}$ & \multirow{2}{*}{$\mathbf{0 . 1 5 5}$} \\
\hline \multirow{2}{*}{ Multi } & $\mathbf{N}$ & $\mathbf{4 0}$ & $\mathbf{5 0}$ & $\mathbf{9 0}$ & \\
\cline { 2 - 5 } & $\%$ & $\mathbf{4 0 . 0 \%}$ & $\mathbf{5 0 . 0 \%}$ & $\mathbf{4 5 . 0 \%}$ & \\
\hline \multirow{2}{*}{ Total } & $\mathbf{N}$ & $\mathbf{1 0 0}$ & $\mathbf{1 0 0}$ & $\mathbf{2 0 0}$ & \\
\cline { 2 - 5 } & $\%$ & $\mathbf{1 0 0 . 0 \%}$ & $\mathbf{1 0 0 . 0 \%}$ & $\mathbf{1 0 0 . 0 \%}$ & \\
\hline
\end{tabular}

There was no significant difference between groups regard co morbidity (Table 3).

Table (3): Co morbidity distribution between studied groups

\begin{tabular}{|c|c|c|c|c|c|}
\hline \multicolumn{2}{|c|}{$\begin{array}{ll}\text { Co-morbidity } & \text { Groups } \\
\end{array}$} & $\begin{array}{c}\text { Corticosteroid } \\
\text { Group (100) }\end{array}$ & $\begin{array}{c}\text { Control } \\
\text { Group }(\mathbf{1 0 0})\end{array}$ & Total & $\mathbf{P}$ \\
\hline \multirow{2}{*}{$-V E$} & $\mathbf{N}$ & 85 & 90 & 175 & \multirow{4}{*}{0.285} \\
\hline & $\%$ & $85.0 \%$ & $90.0 \%$ & $87.5 \%$ & \\
\hline \multirow{2}{*}{$+\mathrm{VE}$} & $\mathbf{N}$ & 15 & 10 & 25 & \\
\hline & $\%$ & $15.0 \%$ & $10.0 \%$ & $12.5 \%$ & \\
\hline \multirow{2}{*}{ Total } & $\mathbf{N}$ & 100 & 100 & 200 & \\
\hline & $\%$ & $100.0 \%$ & $100.0 \%$ & $100.0 \%$ & \\
\hline
\end{tabular}

There was no significant difference between groups regard causes of CS and the major causes were previous $\mathrm{CS}$ and placenta previa (Table 4). 
Table (4): Cause of CS distribution between studied groups

\begin{tabular}{|c|c|c|c|c|c|}
\hline \multicolumn{2}{|c|}{$\begin{array}{ll}\text { Causes of CS } & \text { Groups } \\
\end{array}$} & $\begin{array}{c}\text { Corticosteroid } \\
\text { Group (100) }\end{array}$ & $\begin{array}{c}\text { Control } \\
\text { Group (100) }\end{array}$ & Total & $\mathbf{P}$ \\
\hline \multirow{2}{*}{ Previous C.S } & $\mathbf{N}$ & 35 & 30 & 65 & \multirow{8}{*}{0.816} \\
\hline & $\%$ & $35.0 \%$ & $30.0 \%$ & $32.5 \%$ & \\
\hline \multirow{2}{*}{ Placenta previa } & $\mathbf{N}$ & 35 & 35 & 70 & \\
\hline & $\%$ & $35.0 \%$ & $35.0 \%$ & $35.0 \%$ & \\
\hline \multirow{2}{*}{$\begin{array}{l}\text { Cephalopelvic } \\
\text { disproportion }\end{array}$} & $\mathbf{N}$ & 20 & 25 & 45 & \\
\hline & $\%$ & $20.0 \%$ & $25.0 \%$ & $22.5 \%$ & \\
\hline \multirow{2}{*}{ Malpresentation } & $\mathbf{N}$ & 10 & 10 & 20 & \\
\hline & $\%$ & $10.0 \%$ & $10.0 \%$ & $10.0 \%$ & \\
\hline \multirow{2}{*}{ Total } & $\mathbf{N}$ & 100 & 100 & 200 & \\
\hline & $\%$ & $100.0 \%$ & $100.0 \%$ & $100.0 \%$ & \\
\hline
\end{tabular}

There was no significant difference between groups regards postpartum $\mathrm{Hg}$ or maternal complication in general (Table 5).

Table (5): Maternal outcome and complication distribution between groups

\begin{tabular}{|c|c|c|c|c|c|c|}
\hline \multicolumn{3}{|l|}{ Parameters } & $\begin{array}{l}\text { Corticosteroid } \\
\text { Group }(100)\end{array}$ & $\begin{array}{c}\text { Control } \\
\text { Group (100) }\end{array}$ & Total & $\mathbf{P}$ \\
\hline \multirow{4}{*}{$\begin{array}{c}\text { Postpartum } \\
\text { hg }\end{array}$} & \multirow{2}{*}{$-\mathbf{V E}$} & $\mathbf{N}$ & 85 & 90 & 175 & \multirow{4}{*}{0.285} \\
\hline & & $\%$ & $85.0 \%$ & $90.0 \%$ & $87.5 \%$ & \\
\hline & \multirow{2}{*}{$+\mathrm{VE}$} & $\mathbf{N}$ & 15 & 10 & 25 & \\
\hline & & $\%$ & $15.0 \%$ & $10.0 \%$ & $12.5 \%$ & \\
\hline \multirow{4}{*}{$\begin{array}{c}\text { Maternal } \\
\text { complication }\end{array}$} & \multirow{2}{*}{$-V E$} & $\mathbf{N}$ & 80 & 70 & 150 & \multirow{4}{*}{0.127} \\
\hline & & $\%$ & $80.0 \%$ & $70.0 \%$ & $75.0 \%$ & \\
\hline & \multirow{2}{*}{$+\mathrm{VE}$} & $\mathbf{N}$ & 20 & 30 & 50 & \\
\hline & & $\%$ & $20.0 \%$ & $30.0 \%$ & $25.0 \%$ & \\
\hline \multirow{2}{*}{\multicolumn{2}{|c|}{ Total }} & $\mathbf{N}$ & 100 & 100 & 200 & \\
\hline & & $\%$ & $100.0 \%$ & $100.0 \%$ & $100.0 \%$ & \\
\hline
\end{tabular}

APGAR1 was significantly higher among corticosteroid group, overall respiratory complication was significantly lower among corticosteroid group, RD,
NEED OF NICU and MV and mortality were lower among the same group than control but not significantly (Table 6). 
Table (6): Baby outcome and complication distribution between groups

\begin{tabular}{|c|c|c|c|c|c|}
\hline \multicolumn{3}{|c|}{$\begin{array}{ll}\text { Parameters } & \text { Groups } \\
\end{array}$} & $\begin{array}{l}\text { Corticosteroid } \\
\text { Group (100) }\end{array}$ & $\begin{array}{c}\text { Control } \\
\text { Group }(100)\end{array}$ & $\mathbf{P}$ \\
\hline \multicolumn{3}{|c|}{ APGAR1 } & $7.2 \pm 0.75$ & $6.65 \pm 0.72$ & $\mathbf{0 . 0 0 1 * *}$ \\
\hline \multicolumn{3}{|c|}{ APGAR5 } & $8.41 \pm 0.87$ & $8.25 \pm 1.01$ & $\mathbf{0 . 2 3 2}$ \\
\hline \multirow{4}{*}{ NICU } & \multirow{2}{*}{ Not } & $\mathbf{N}$ & 91 & 83 & \multirow{4}{*}{0.093} \\
\hline & & $\%$ & $91.0 \%$ & $83.0 \%$ & \\
\hline & \multirow{2}{*}{ Needed } & $\mathbf{N}$ & 9 & 17 & \\
\hline & & $\%$ & $9.0 \%$ & $17.0 \%$ & \\
\hline \multirow{4}{*}{ RD } & \multirow{2}{*}{$-V E$} & $\mathbf{N}$ & 93 & 89 & \multirow{4}{*}{0.323} \\
\hline & & $\%$ & 93.0\% & $89.0 \%$ & \\
\hline & \multirow{2}{*}{$+\mathrm{VE}$} & $\mathbf{N}$ & 7 & 11 & \\
\hline & & $\%$ & $7.0 \%$ & $11.0 \%$ & \\
\hline \multirow{4}{*}{$\begin{array}{l}\text { Respiratory } \\
\text { comp }\end{array}$} & \multirow{2}{*}{$-V E$} & $\mathbf{N}$ & 89 & 73 & \multirow{4}{*}{$0.004 *$} \\
\hline & & $\%$ & $89.0 \%$ & $73.0 \%$ & \\
\hline & \multirow{2}{*}{$+\mathrm{VE}$} & $\mathbf{N}$ & 11 & 27 & \\
\hline & & $\%$ & $11.0 \%$ & $27.0 \%$ & \\
\hline \multirow{4}{*}{ MV } & \multirow{2}{*}{$-V E$} & $\mathbf{N}$ & 95 & 88 & \multirow{4}{*}{0.08} \\
\hline & & $\%$ & $95.0 \%$ & $88.0 \%$ & \\
\hline & \multirow{2}{*}{$+\mathrm{VE}$} & $\mathbf{N}$ & 5 & 12 & \\
\hline & & $\%$ & $5.0 \%$ & $12.0 \%$ & \\
\hline \multirow{4}{*}{$\begin{array}{l}\text { Neonatal } \\
\text { mortality }\end{array}$} & \multirow{2}{*}{$-V E$} & $\mathbf{N}$ & 98 & 92 & \multirow{4}{*}{0.052} \\
\hline & & $\%$ & $98.0 \%$ & $92.0 \%$ & \\
\hline & \multirow{2}{*}{$+\mathrm{VE}$} & $\mathbf{N}$ & 2 & 8 & \\
\hline & & $\%$ & $2.0 \%$ & $8.0 \%$ & \\
\hline \multirow{2}{*}{\multicolumn{2}{|c|}{ Total }} & $\mathbf{N}$ & 100 & 100 & \\
\hline & & $\%$ & $100.0 \%$ & $100.0 \%$ & \\
\hline
\end{tabular}

\section{DISCUSSION}

In the current study there was no statistically significant difference between the two studied groups as regards neonatal admission to NICU. Age and GA were distributed without significant difference between groups.

The present study agreed with Sotiriadis et al. (2018), who found that there was no role of corticosteroid in elective section at term for reducing incidence of NICU admission with no statistically significant difference in the overall rate of admissions to NICU. Roberts et al. (2017) exhibited that treatment with antenatal corticosteroids at term was associated with less need to neonatal respiratory support; with a reduction in the need for mechanical ventilation/ continuous positive airway pressure (CPAP), and less time requiring oxygen supplementation but with no statistically significant difference between the intervention and control groups.

Sotiriadis et al. (2018) have done a research on babies born at term by elective cesarean section. Prophylactic corticosteroids appeared to significantly decrease the risk of admission to the neonatal intensive care unit for respiratory morbidity, which may be explained by the fewer number of candidates included in this study, and their larger number of candidates might had the accentuation effect over the insignificant difference we noticed in this study. 
In the current study, there was no statistically significant difference between the two studied groups as regards, incidence of RDS. In agreement with this result, Sotiriadis et al. (2018) conducted that no statistically significant reduction was found in the incidence of neonatal respiratory distress syndrome. Ventolini et al. (2011) found that, to some extent, the usage of antenatal dexamethasone in the intervention group had improved neonatal outcomes as regards the incidence of respiratory morbidity, but with no statistically significant difference, which support our results on term babies while they conducted their research on pre-term babies.

On the other hand, this does not agree with Roberts et al. (2017) who stated that treatment with antenatal corticosteroids is associated with an overall reduction in incidence of RDS.

In the current study, there was no statistically significant difference between the two studied groups as regards, incidence of transient tachypnea of the newborn. Sotiriadis et al. (2018) agreed with this study as they conducted that no statistically significant reduction was found in the incidence of transient tachypnea of the newborn.

In the current study, there was no statistically significant difference between the two studied groups as regards the need for mechanical ventilation. In agreement with results of the current study, Sotiriadis et al. (2018) concluded that no statistically significant reduction was found in the need for mechanical ventilation. Gouyon et al. (2010) agreed with the current study as the incidence of transient tachypnea of the newborn and RDS markedly dropped from $10 \%$ at 37 weeks of gestation to $0 \%$ at 39 weeks of gestation.

PG represented $60 \%$ of 1 st group, while represented $50 \%$ of 2 nd group without significant difference between them. There was no significant difference between groups regard co morbidity. There was no significant difference between groups as regard causes of CS, and the major causes were previous CS and placenta previa.

There was no significant difference between groups as regards postpartum hemorrhage or maternal complication in general. APGAR1 was significantly higher among corticosteroid group. Overall respiratory complication was significantly lower among corticosteroid group, RD, need of NICU and MV, and mortality were lower among the same group than control but not significantly.

Balci et al. (2010) APGAR score at 1 minute was7.408 \pm 0.85 and $7.86 \pm 0.78$. APGAR score at 5 minutes was $7.98 \pm$ 0.74 and $8.60 \pm 0.75$ for group I and group II.

Regarding the post-delivery foetal complication: neonates require resuscitation in group I $14 \%$ while in group II $32 \%$. RDS in group I $4 \%$ while in group II $16 \%$.

There was a statistical significant difference between the two studied groups regarding the post-delivery foetal complication.

Porto et al. (2011) stated that treatment with corticosteroids failed to reduce the risk of any respiratory morbidity. Necessity for ventilatory support was also similar. Antenatal treatment with corticosteroid in women at 34-36 weeks of 
pregnancy at risk of imminent premature delivery is ineffective in reducing respiratory disorders in the babies.

Shanks et al. (2010) concluded that a single course of intramuscular glucocorticoids after 34 weeks in pregnancies with documented fetal lung immaturity significantly increases fetal lung maturity and decrease the neonatal morbidity.

\section{CONCLUSION}

A single course of corticosteroids (four $6 \mathrm{mg}$ doses dexamethasone administered intramuscular every 12 hours) should be considered for women undergoing planned cesarean at 37 or more week's gestation. Incidence of respiratory problems increases in preterm infants.

\section{REFERENCES}

1. Ahmed MR, Sayed Ahmed WA and Mohammed TY. (2015): Antenatal steroids at 37 weeks, does it reduce neonatal respiratory morbidity? A randomized trial. J Matern Fetal Neonatal Med., 28:1486-90.

2. Balci O, Ozdemir $S$ and Mahmoud AS. (2010): The effect of antenatal steroids on fetal lung maturation between the 34th and 36th week of pregnancy. Gynecol Obstet Invest., 70(2):95-99.

3. Ceriani CJM. (2015): Late-preterm infants, a growing challenge in both the short and long term. Arch Argent Pediatr., 113:482-4.

4. Gouyon JB, Vintejoux A, Sagot $P$ and Burguet A. (2010): Neonatal outcome associated with singleton birth at 34-41 weeks of gestation. International Journal of Epidemiology, 39(3):769-76.

5. Martin JA, Hamilton BE, Osterman MJ, Curtin SC and Matthews TJ. (2015): Births: final data for 2013. Natl Vital Stat Rep., 64:165.
6. Nada AM, Shafeek MM, El Maraghy MA, Nageeb AH, Salah El Din AS and Awad MH. (2016): Antenatal corticosteroid administration before elective caesarean section at term to prevent neonatal respiratory morbidity: a randomized controlled trial. Eur J Obstet Gynecol Reprod Biol., 199:88-91.

7. Porto AMF, Coutinho IC, Correia JB and Amorim MMR. (2011): Effectiveness of antanatal corticosteroids in reducing respiratory disorders in late preterm Infants: randomised clinical trial. British Medical Journal, 342(7802): 1696-1702.

8. Prefumo F, Ferrazzi E and Di Tommaso M. (2016): Neonatal morbidity after cesarean section before labor at $34(+0)$ to $38(+6)$ weeks: a cohort study. J Matern Fetal Neonatal Med., 29:1334-8.

9. Roberts D, Brown J, Medley $N$ and Dalziel SR. (2017): Antenatal corticosteroids for accelerating fetal lung maturation for women at risk of preterm birth. Cochrane Database of Systematic Reviews, 3: CD004454.

10. Shamseer L, Moher $D$ and Clarke $M$. (2015): PRISMA-P Group. Preferred reporting items for systematic review and meta-analysis protocols (PRISMA-P) 2015: elaboration and explanation. BMJ., 349: 7647.

11. Shanks A, GrossG, Shim T ,Allsworth J , Sadovsky $Y$ and Bildirici I. (2010): Administration of steroids after 34 weeks of gestation enhances fetal lung maturity profiles, Am J Obstet Gynecol., 203(1):47-52.

12. Sotiriadis A, Makrydimas G, Papatheodorou S, Ioannidis JP and McGoldrick E. (2018): Corticosteroids for preventing neonatal respiratory morbidity after elective caesarean section at term. Cochrane Database Syst Rev., 8(8): CD006614.

13. Ventolini G, Neiger R, Mathews L, Adragna $N$ and Belcastro $M$. (2011): Incidence of Respiratory Disorders in Neonates Born Between 34 and 36 Weeks of Gestation Following Exposure to Antenatal Corticosteroids Between 24 and 34 Weeks of Gestation. Am J Perinatol., 25(2):79-83. 


\section{دور الكورتيزون الوقائى قبل الجر احة القيصرية الاختيارية فى الجنين الكامل على الوقاية من أمر اض الجن الجهاز التنفسى

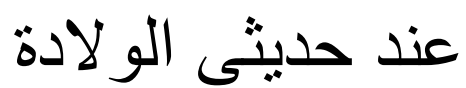

أمير محمد السعيد على, محمد خالد مصطفى, محمد محمد فرحات الت لات

قسم التوليد وأمراض النساء, كلية الطب، جامعة الأزهر

E-mail: amiratwa1988@gmail.com

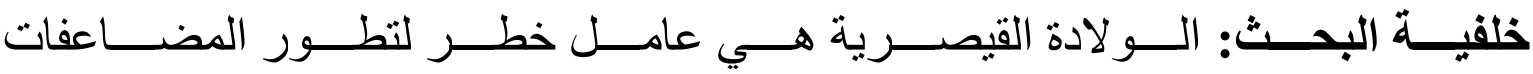

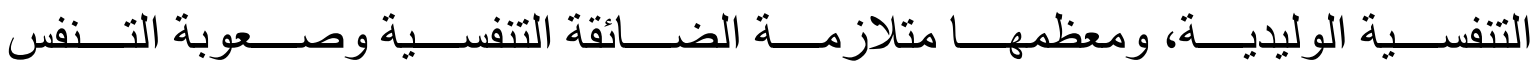

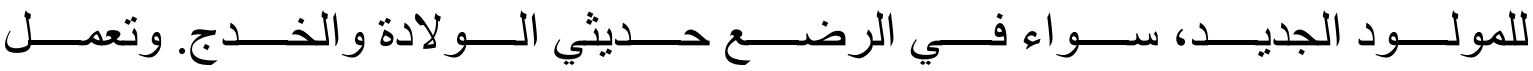

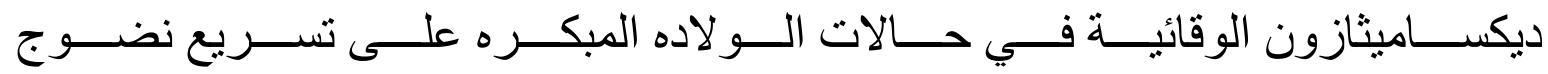
الرئة وتقليل حدوث المر اضة التنفسية.

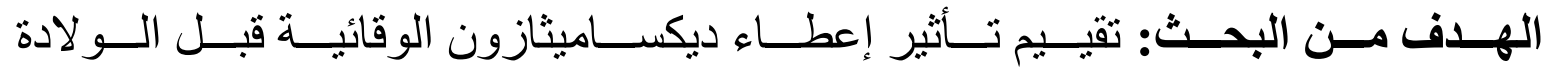

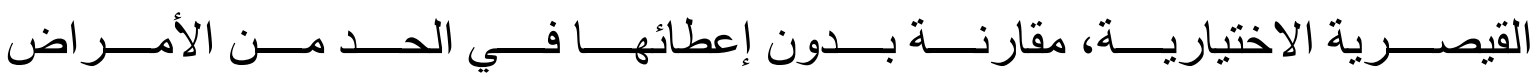
التنفسية الوليدية والدخول بالر عاية الخاصة بمضاعفات الجهاز التنفسي.

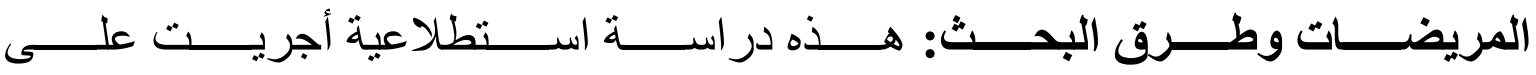

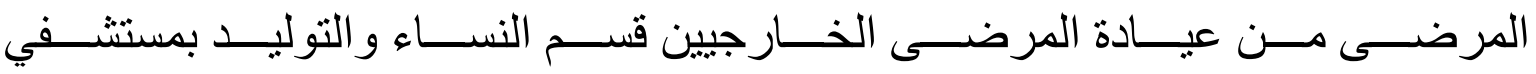

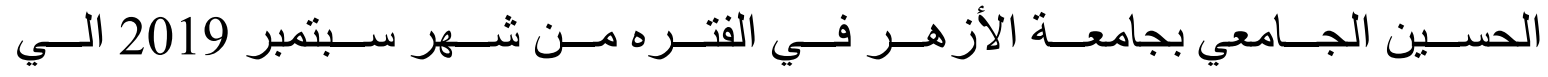

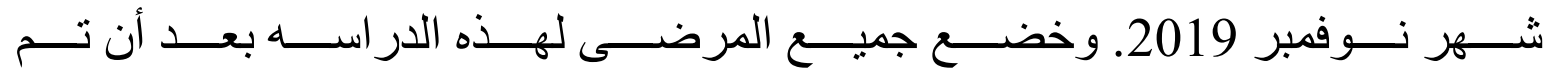

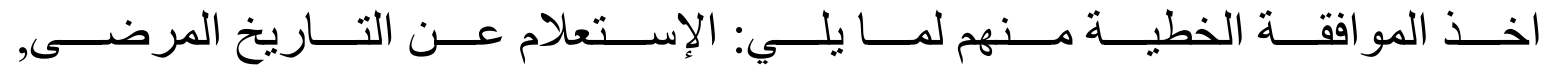

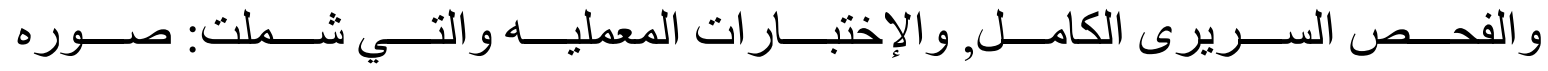

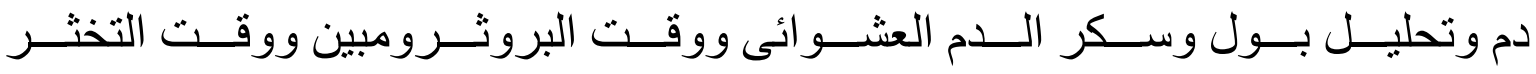

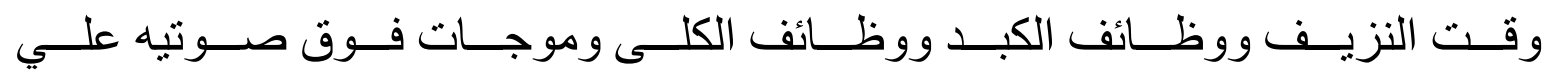

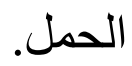




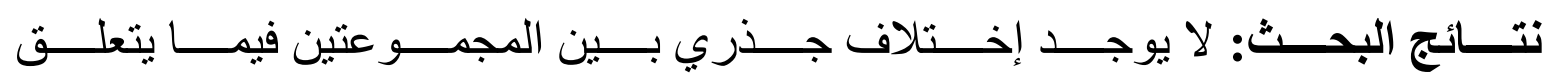

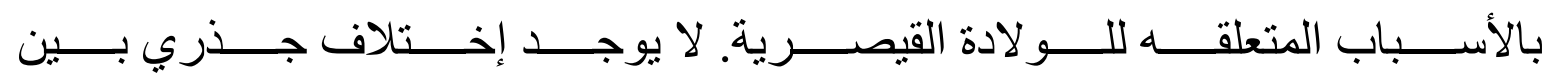

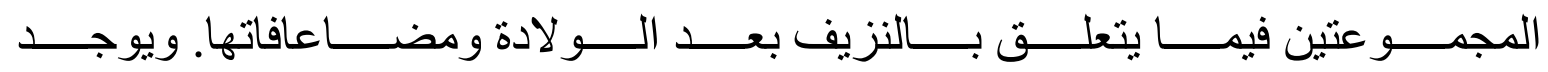

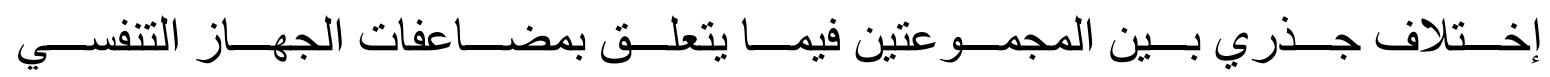

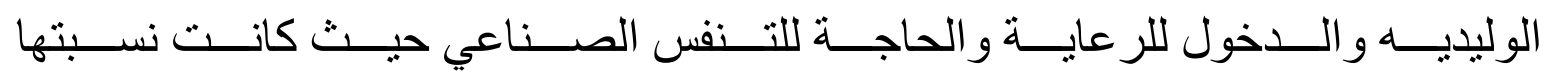

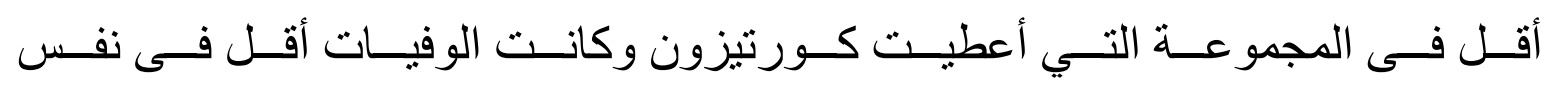
المجمو عه مقارنة بالمجمو عة الظابطة.

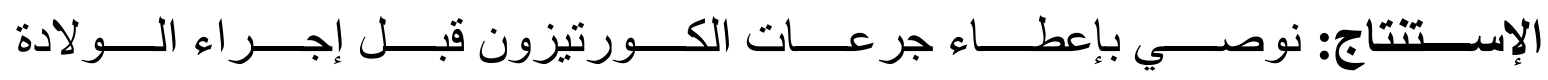
القيصرية الاختيارية.

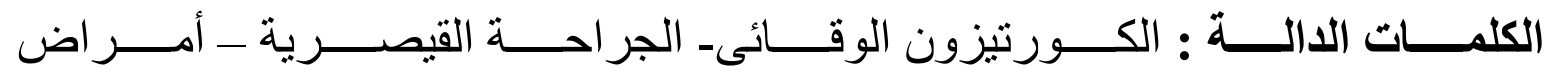

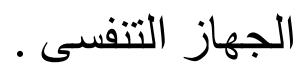

